\title{
Sesmic Performance of Rc Framed Structure with and Without Infill
}

\author{
Bhavani chowdary Talasila ${ }^{1}$ \\ Post Graduate student, Dept. of civil engineering Acharya Nagarjuna University, Guntur.
}

\begin{abstract}
Performance based seismic engineering is the modern approach of earthquake resistant engineering. It is an attempt to predict buildings with predictable seismic performance. Therefore, the objectives such as life safety, collapse prevention, or immediate occupancy are used to define the state of the building following a design earthquake. This paper presents the effective computer based seismic performance analysis technique which reduces the tedious calculations and predict exact results. Push over analysis is proposed to estimate the peak responses in load and lateral displacements. The comparison are made in the lower, middle and higher rise structures by using the push over analysis, the performance of the structures can be obtained. Three different structures are taken into consideration for the analysis and their load distributions and lateral displacements are obtained. The major part of the discussion in this paper will be devoted to considerations associated with providing ductility in members and structures. The discussion in this paper will be confined to monolithically cast reinforced-concrete buildings. The concepts of seismic demand and capacity are introduced and elaborated on.
\end{abstract}

Keywords: push over analysis, plastic hinge length, masonry infill, Seismic demand, Equivalent diagonal strut, Hinge damage states.

\section{Introduction}

Non-linear analysis has gained importance in evaluating the structural performance,. they became popular in predicting the structures ability, identifying the patterns and level of damages for assessing the structure in elastic behavior, understanding the failure modes. The seismic evaluation and retrofitting of existing buildings have been required to use performance based seismic methodologies. Structures designed according to current seismic design regulations or design code should, in general, satisfy the following rules. First, resist minor level of earthquake ground motions without damage; second, resist moderate earthquakes without structural damage, but may experience some non-structural damage; and finally, resist major earthquakes without collapse, but possibly with some structural and non-structural damage. Such qualification of the performance criteria has been introduced in regular seismic design practice. Impact of the structural damage on the society seems quantified through the importance factor without specific quantification of structural performance. .push over analysis is a static nonlinear procedure in which loads are applied incrementally to the framed structures .this method generally involves the lumped plasticity approach. It involves the formation of nonlinear plastic hinges at the frame element end's of during the incremental loading. Plastic hinges are of great interest to the structural engineers and researchers. They studied the length of plastic zone, they knew that the increase in the confinement at the plastic zone increases the ductility of the member and survival of the structure from the extreme events (earthquakes). As graphically presented in Fig. 1, the nonlinear static analysis procedure requires determination of three primary elements: capacity, demand and performance. The capacity spectrum can be obtained through the pushover analysis, which is generally produced based on the first mode response of the structure assuming that the fundamental mode of vibration is the predominant response of the structure. This pushover capacity curve approximates how a structure behaves beyond the elastic limit under seismic loadings. generally the demand spectrum is estimated at $5 \%$ damping spectrum by spectral reduction method.fig 1 defines the performance point, which is the intersection of demand spectrum and capacity spectrum. At the performance point, the resulting responses of the building should then be checked using certain acceptability criteria.

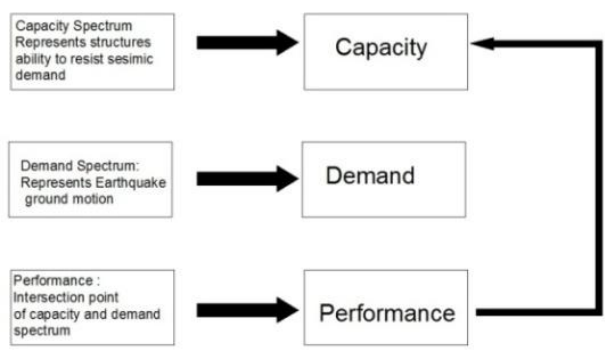

Fig 1 non linear analysis procedure 
Lumped plasticity idealization is a commonly used approach in models for deformation capacity estimates. The ultimate deformation capacity of a component depends on the ultimate curvature and plastic hinge length. The use of different criteria for the ultimate curvature and different plastic hinge length may result in different deformation capacities. Several plastic hinge lengths have been proposed in the literature review.

Table 1.0 Expression for plastic hinge length

\begin{tabular}{|c|c|}
\hline Researchers reference & Length of plastic hinge(lp) \\
\hline Baker(1956) & $\begin{array}{l}\mathrm{K}(\mathrm{z} / \mathrm{d})^{1 / 4} \mathrm{~d} \\
\quad \text { (for RC beams and columns) }\end{array}$ \\
\hline Sawyer(1964) & $0.25 \mathrm{~d}+0.075 \mathrm{z}$ \\
\hline Corley(1966) & $\begin{array}{l}0.5 \mathrm{~d}+0.2 \sqrt{\mathrm{d}}(\mathrm{z} / \mathrm{d}) \\
\text { (for } \mathrm{RC} \text { beams) }\end{array}$ \\
\hline Mattock(1967) & $\begin{array}{l}0.5 \mathrm{~d}+0.05 \mathrm{z} \\
\text { (for RC beams) }\end{array}$ \\
\hline Pristely\&park(1987) & $\begin{array}{l}0.08 \mathrm{z}+6 \mathrm{~d}_{\mathrm{b}} \\
\text { (for RC beams) }\end{array}$ \\
\hline Paulay\&pristely(1992) & $\begin{array}{l}0.08 \mathrm{z}+0.022 \mathrm{~d}_{\mathrm{b}} \mathrm{f}_{\mathrm{y}} \\
\text { (for RC beams, columns) }\end{array}$ \\
\hline Panagikos\&Fardis(2001) & $\begin{array}{l}\text { 1.0h } \\
\text { (for columns under high axial loads) }\end{array}$ \\
\hline
\end{tabular}

Taking all these empirical expressions into account and Paualay and Priestley (1992) is considered, and it is taken in the current paper calculation for plastic hinge length(lp). Masonry infill (MI) walls significantly increases the initial stiffness of the reinforced concrete (RC) frames. They act as a stiffer component and they attract the lateral shear force on the reinforced concrete buildings, there by they reduce the demand on the RC frames. As we know that the behavior of masonry infill walls are unpredictable(significant variations in material properties and modes of failure), since they are in brittle nature.so,this is why there are not treated as non structural elements and their effects are not included in the analysis and design procedure.

How ever some experience shows that masonry infill may have positive and negative effects on the global behavior on the building, so we have to address them properly. Generally Masonry infill (MI) walls confined by reinforced concrete (RC) frames on all four sides play a vital role in resisting the lateral seismic loads on buildings. It has been shown experimentally that MI walls have a very high initial lateral stiffness and low deformability.

According to Moghaddam and Dowling (1987)Introduction of masonry infill in the reinforced concrete frames changes the lateral load transfer mechanism of structure of predominant frame action to predominant truss action. (Murty and Jain 2000), as shown in Figure 2, which is responsible for reduction in bending moments and increase in axial forces in the frame members. In addition, construction of MI is cheaper because it uses locally available material and labor skills. Moreover, it has good sound and heat insulation and waterproofing properties, resulting in greater occupant comforts and economy.

Buildings become irregular in plan and elevation because of uncertain position of walls ,they are built according to the wish of the occupants, so masonry walls with irregular openings can be chosen, the changes can be chosen without considering the adverse effects of the infill because they are not considered as a structural elements. masonry infill are constructed in several ways as shown in fig 3, however MI-RC frames remain regular after it is constructed. Multi storey structures are analyzed without considering the effect of infill panels on the assumption that these infill's ill not resist any kind of load and, however these, infill panels increase the strength and stiffness of the frames considerably and responsible for the unequal distribution of forces.

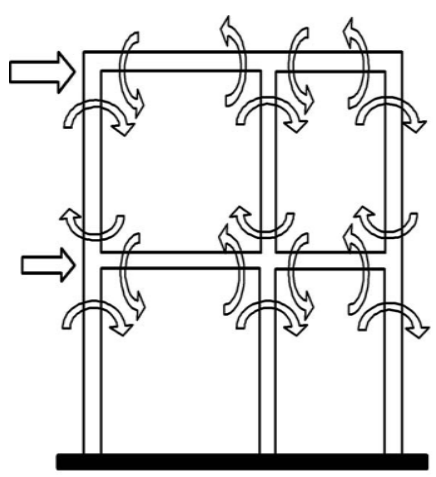

(a) Predominant frame action

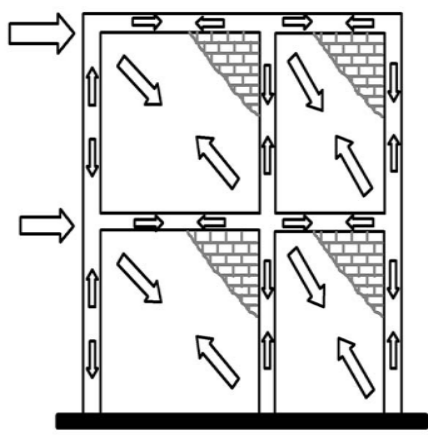

(b) Predominant truss action

Fig 2 lateral load transfer mechanism 


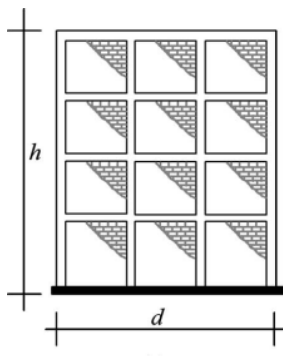

(a)

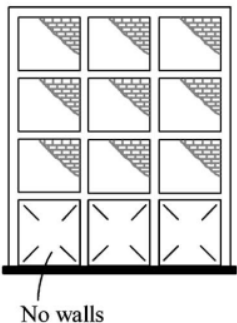

(b)

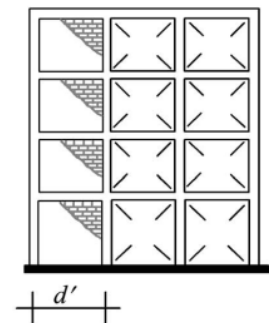

(c)

Fig 3 different arrangements of infill in RC frames

The consideration of stiffening effect of the infill is pre dominant; as it can change the behavior of building in elastic range .effect of infill from elastic to inelastic behavior can be quiet complex.

\section{Description of Structural System And Classification}

Three different structures are considered and they had been studied, description of three structures are given below These structures are resisting on soils with good bearing capacity. All structural weight and super imposed load is carried by the system of reinforced slab and reinforced concrete beams supported by concrete columns. The SAP2000 software is utilized to create the model and carry out the analysis, the buildings are modeled as resisting frames, the loads are applied as per the Indian standards. The study is performed for the seismic zone V as per IS 1893-2002.The buildings are firmly fixed at the bottom and soil interaction is neglected.

\begin{tabular}{|l|l|}
\multicolumn{2}{|c|}{ Model data of the structures } \\
\hline Plan dimensions & $\begin{array}{l}18 \mathrm{X} 18 \mathrm{M}, 30 \mathrm{X} 30 \mathrm{M} \text { (for mid and } \\
\text { high rise) }\end{array}$ \\
\hline No .of stories & $\mathrm{G}+4, \mathrm{G}+8$ and G+20 \\
\hline Storey height & $\begin{array}{l}3 \mathrm{~m} \\
\text { (low, 3.1m for mid rise } \\
\text { structure) } \\
3.5 \mathrm{~m} \\
\text { ( high rise structure) }\end{array}$ \\
\hline Type of building use & apartment \\
\hline Material Properties & $27.38 \times 10^{6} \mathrm{KN} / \mathrm{m}^{2}$ \\
\hline Young's modulus of M30 (E) & $\mathrm{M} 30$ \\
\hline Grade of concrete & $\mathrm{Fe} 415$ \\
\hline Grade of steel & $25 \mathrm{KN} / \mathrm{m}^{3}$ \\
\hline Density of reinforced concrete & $18 \mathrm{KN} / \mathrm{m}^{3}$ \\
\hline Density of brick masonry & $120 \mathrm{~mm}$ \\
\hline Member properties & $\left(\right.$ low, $\mathrm{mid}^{2}$ rise structure) \\
\hline Thickness of slab & $150 \mathrm{~mm}$ (high rise) \\
\hline Thickness of wall & $230 \mathrm{~mm}$ \\
\hline Live load & $3 \mathrm{kN} / \mathrm{m}^{2}$ \\
\hline Seismic Zone & $\mathrm{V}$ \\
\hline Zone factor, Z & 0.36 \\
\hline Importance factor, I & 1.00 \\
\hline Response reduction factor, R & 5.00 \\
\hline
\end{tabular}

\section{Modeling And Analysis}

In this project, structures are selected as per the national building code (NBC), different structures are selected and categorized as low rise $(\mathrm{G}+4)$, mid rise $(\mathrm{G}+9)$ and high rise $(\mathrm{G}+20)$ structures. Low rise structure dimensions are as follows, the beam size is $0.23 \mathrm{X} 0.3 \mathrm{M}$ the column dimensions are as follows, they are of size 0.45X0.45M.they are modeled in the SAP 2000.shear calculations are done as per IS 456. Here in this software infill as provided as diagonal strut.

In seismic analysis of RC buildings, analysis of unfilled frames are studied. Many investigators have proposed the various approximations for the width of equivalent diagonal strut. Polyav(1956), and his precedes proposed the width of strut depends on the length of contact between walls and columns .they proposed the range is in between one-fourth to one-tenth of the length of the panel. Stafford smith(1966) developed the formulations for $\alpha_{h}$ and $\alpha_{L}$ on the basis of beam on an elastic foundation. The following equations are proposed to determine $\alpha_{\mathrm{h}}$ and $\alpha_{\mathrm{L}}$, which depends on the relative stiffness of the frame and infill, and on the geometry of the panel 
$\alpha_{h}=\pi / 2\left[\frac{E_{f f c h}}{E_{m} t \sin 2 \theta}\right]^{1 / 4} \quad \alpha_{L}=\pi / 2\left[\frac{E_{f l b} L}{E_{m} \sin 2 \theta}\right]^{1 / 4}$

Where $\quad E_{\mathrm{f}}$ and $\mathrm{E}_{\mathrm{m}}$ are elastic modulus of masonry wall and frame material, respectively

$\mathrm{T}, \mathrm{h}, \mathrm{L}$ are the thickness, height and length of the infill respectively

$\mathrm{I}_{\mathrm{c},} \mathrm{I}_{\mathrm{b}}$ are the moment of inertia of beam and column respectively

$\theta=\tan ^{-1}(\mathrm{~h} / \mathrm{L})$

Hendry (1963) proposed the equation for the equivalent diagonal strut width w, where the strut is assumned to be a uniform compressive stress

$\mathrm{w}=1 / 2 \sqrt{\alpha_{\mathrm{h}}}{ }^{2}+\alpha_{\mathrm{L}}^{2}$

Holmes(1963) recommended a width of the diagonal strut is equal to the one-third of the diagonal length of the panel ,here as New Zealand Code (NZS4320) specifies that a width equal to one quarter of its length.

Modal results for these structures are tabulated, for mode I.

\begin{tabular}{|l|l|l|l|}
\hline S.no & Type of structure & $\begin{array}{l}\text { Modal period } \\
(\mathrm{sec})\end{array}$ & $\begin{array}{l}\text { Frequency } \\
(\mathrm{cyc} / \mathrm{sec})\end{array}$ \\
\hline 1 & $\mathrm{G}+4$ & 0.6740 & 1.4835 \\
\hline 2 & $\mathrm{G}+8$ & 1.1048 & 0.9051 \\
\hline 3 & $\mathrm{G}+20$ & 2.2034 & 0.4538 \\
\hline
\end{tabular}

These are modeled in the SAP 2000V 15.00 the figure 4 shows the low,mid and high structure without infill

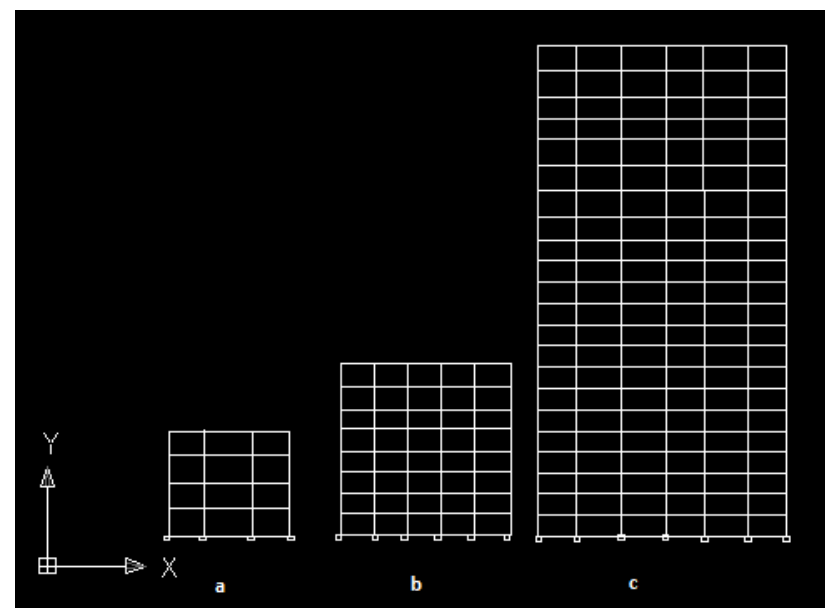

These are a) G+4,b) G+8 \& c) G+20 structures without infill

Similarly the low, mid and high rise structures with infill are shown, they are drawn as per the specifications

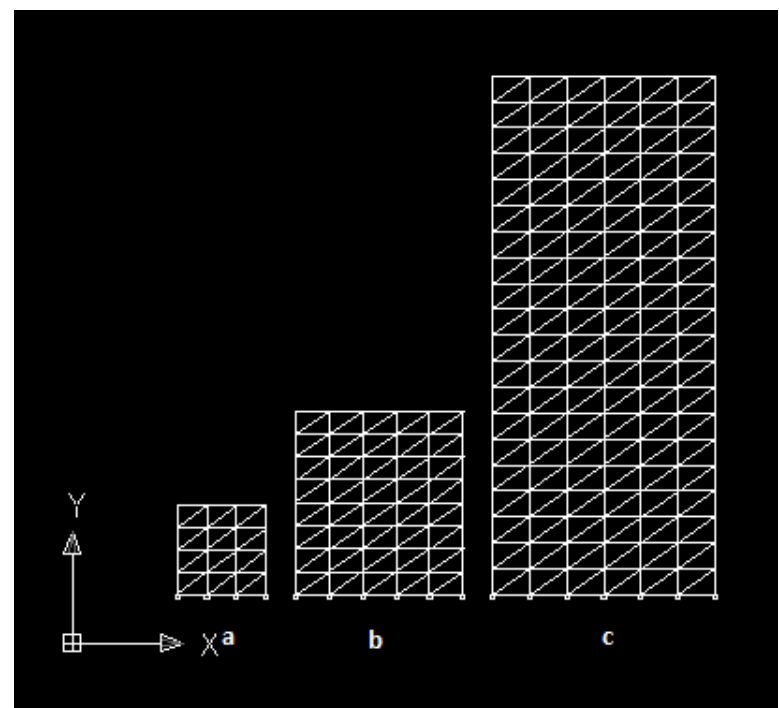

Fig 5 a)represents the Low rise,b) mid rise and c) high rise with infill 
The pushover analysis consists of the application of gravity loads and a lateral load pattern. The frames were subjected to gravity analysis and simultaneous lateral loading. Gravity loads were in place during lateral loading. In all cases, lateral forces were applied monotonically in a step-by-step nonlinear static analysis. The applied lateral forces were proportional to the product of mass and the first mode shape amplitude at each story level under consideration. The first mode is taken into consideration since it takes about $90 \%$ of the modal mass of the structure.

According to Hayri Baytan Ozmen and Mehmet Inel In pushover analysis, the structural behavior is characterized by a capacity curve that represents the relationship between the base shear force and the roof displacement. This is a convenient way of representation in practice, and can be explicitly visualized by the engineer. It is recognized that roof displacement was used for the capacity curve because it is widely accepted. Pushover analysis results (capacity curve, plastic hinge mechanisms) are discussed in the following.

\section{Plastic Hinge Mechanisms}

SAP2000 implements the plastic hinge properties described in FEMA-356 (or ATC-40). As shown in Fig. 6, five points labeled A, B, C, D, and E define the force-deformation behavior of a plastic hinge. The values assigned to each of these points vary depending on the type of element, material properties, longitudinal and transverse steel content, and the axial load level on the element. SAP2000 provides default-hinge properties and recommends PMM hinges for columns and M3 hinges for beams. Once the structure is modeled with section properties, steel content and the loads on it, default hinges are assigned to the elements (PMM for columns and M3 for beams). There is no extensive calculation for each member.

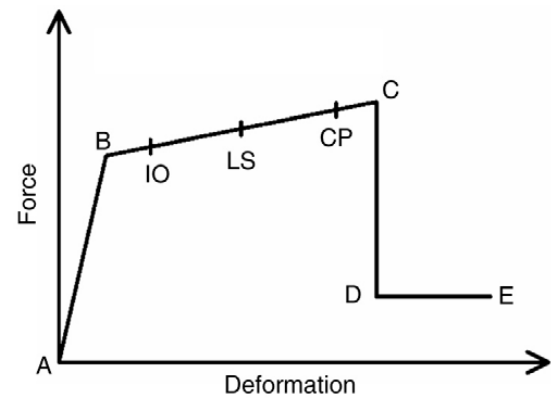

Fig 6: represents the force-deformation for a typical plastic hinge.

Several plastic hinges have been proposed, for the user-defined hinge properties, the plastic hinge length values are considered as given in the equation, which is proposed by paulay and priestley et al $\mathrm{Lp}=0.08 \mathrm{z}+0.022 \mathrm{~d}_{\mathrm{b}} \mathrm{f}_{\mathrm{y}}$

$\mathrm{Lp}$ is the plastic hinge length, $\mathrm{H}$ is the section depth, $\mathrm{L}$ is the critical distance from the critical section of the plastic hinge to the point of contra flexure, and fy and $d_{b}$ are the expected yield strength and the diameter of longitudinal reinforcement, respectively. A fundamental question in performance-based design is to validate the appropriateness of the selected performance levels, the specific parameters used to define their minimum performance, and the seismic hazard definitions. For the case of three performance levels (serviceability, damage control and life safety or collapse prevention), three corresponding structural characteristics (stiffness, strength and deformation capacity) dominate the performance as illustrated in Fig.7. If more intermediate performance levels are selected, then it becomes difficult to define which structural characteristics dominate the performance. It can be argued that different performance objectives may impose conflicting demands on strength and stiffness. Much research is needed to associate the displacement or drift limits with the damage states and the stated general performance objectives. The displacements or drift limits are also functions of the structural system and its ability to deform (ductility).

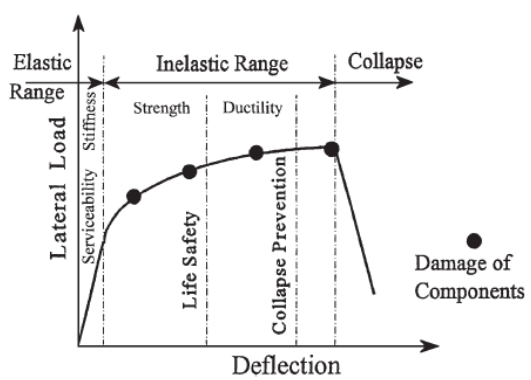

Fig 7: represents the typical performance of the structure. 
The push over results are plotted for the structures the results are shown below

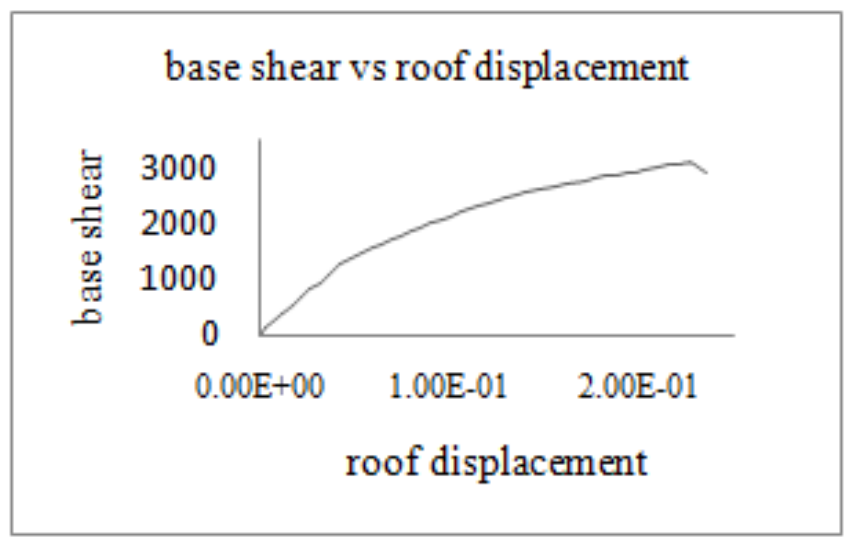

Graph above represents the low rise structure without infill

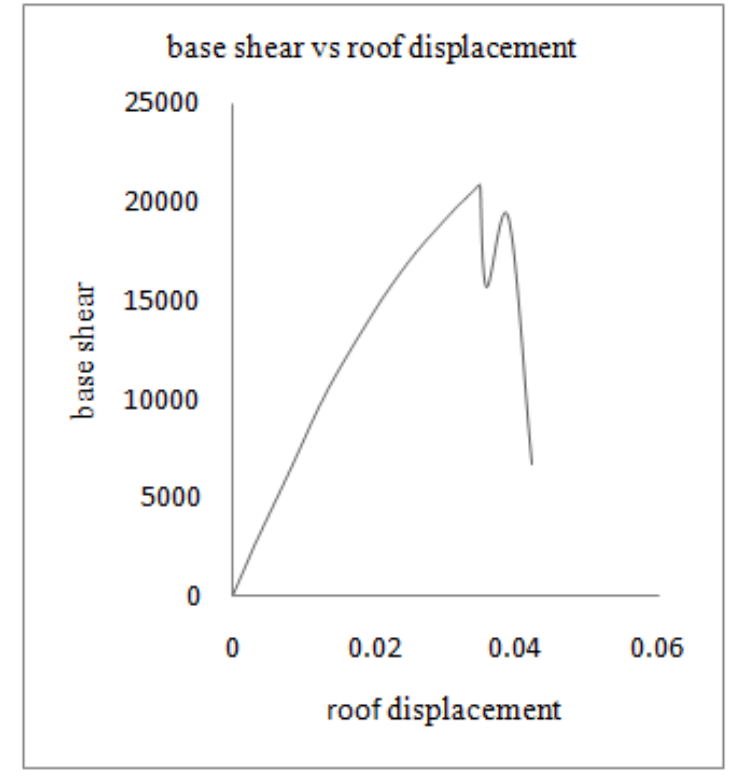

The above graph states that push over result for the low rise structure with infill Similarly the push over results are compared for the low rise structure ith and without infill, the graph below represents the comparison of structure with and without infill

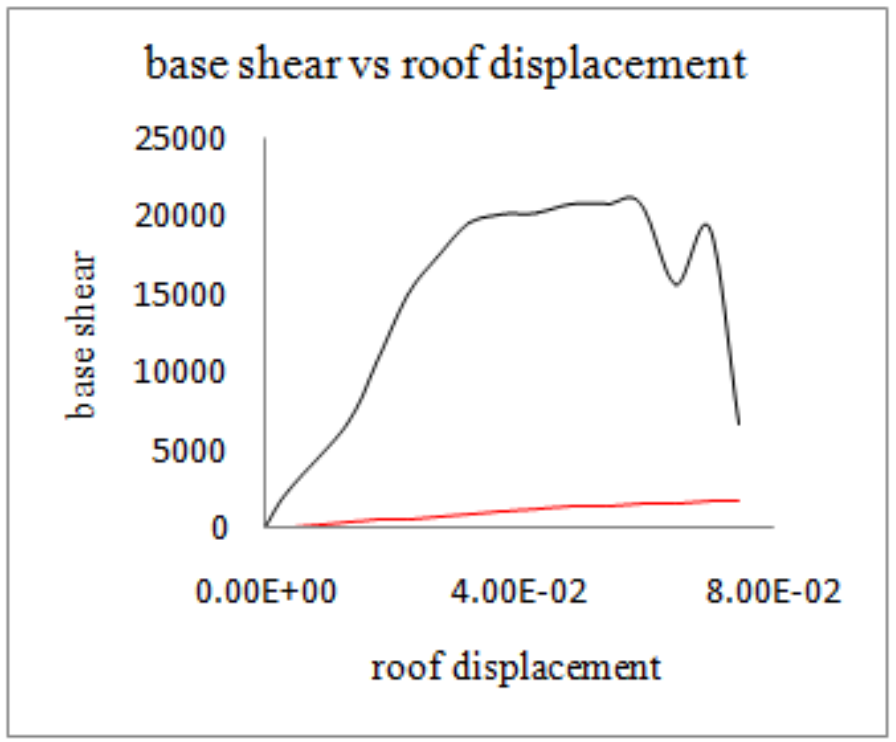


the black color line indicates the base shear for infill structure and red represents the base shear without infill. The mid rise structure graphs are drawn

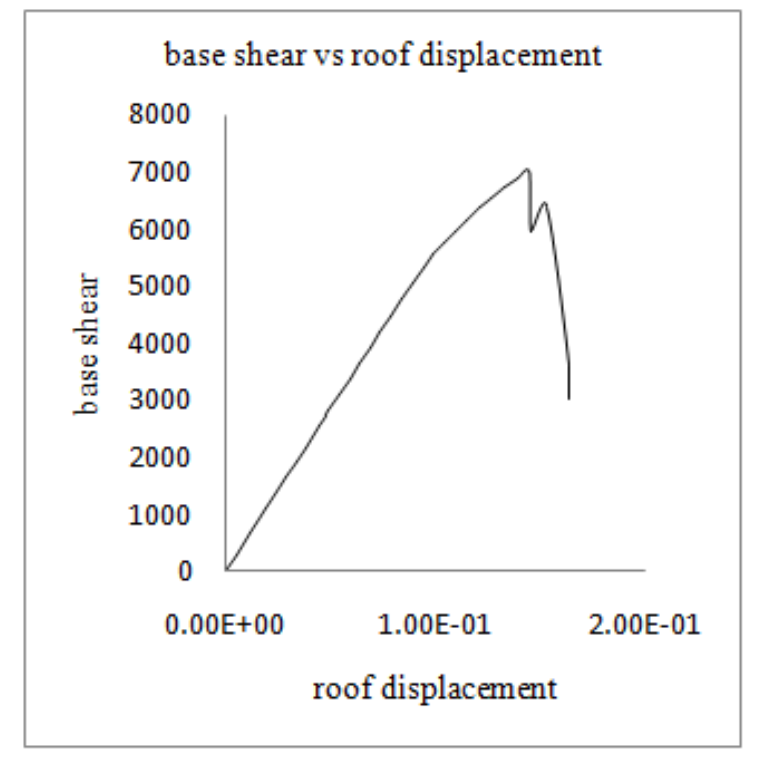

The graph above clearly explains the value of base shear and roof displacement for mid rise structure without infill. The mid rise structure with infill push over result is as follows

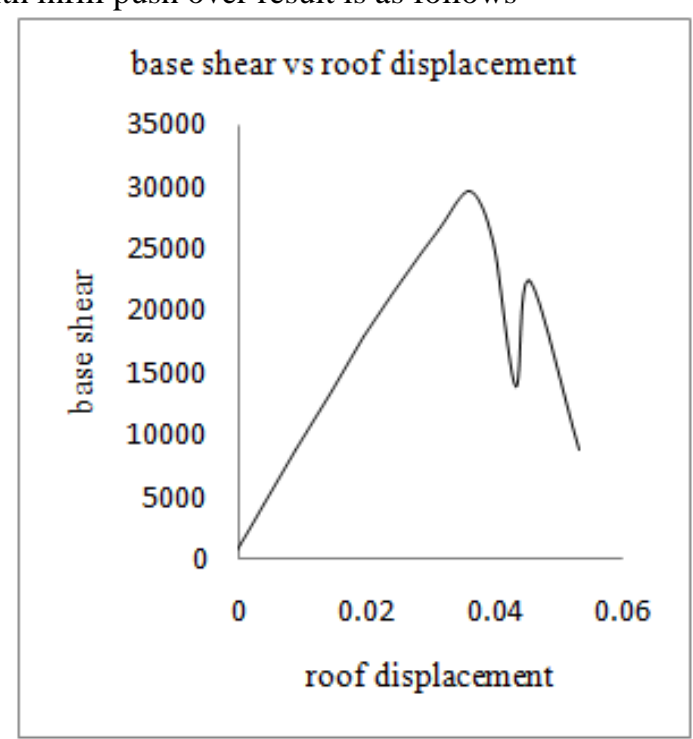

Then the base shear versus roof displacement graph is drawn for the both with and without infill is drawn

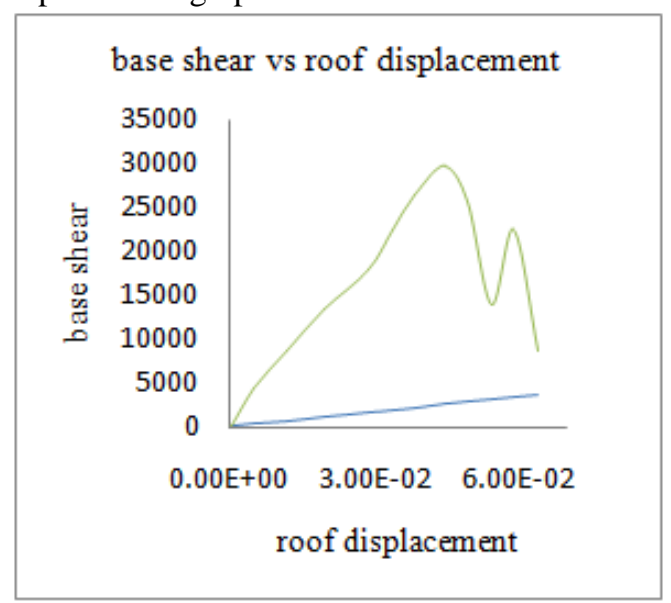


The graph explicitly explains about the how the base shear is distributed in both fill and without infill.

The graph below shows the push over result for the high rise structure with and without infill and the comparison graph is drawn as per the results obtained

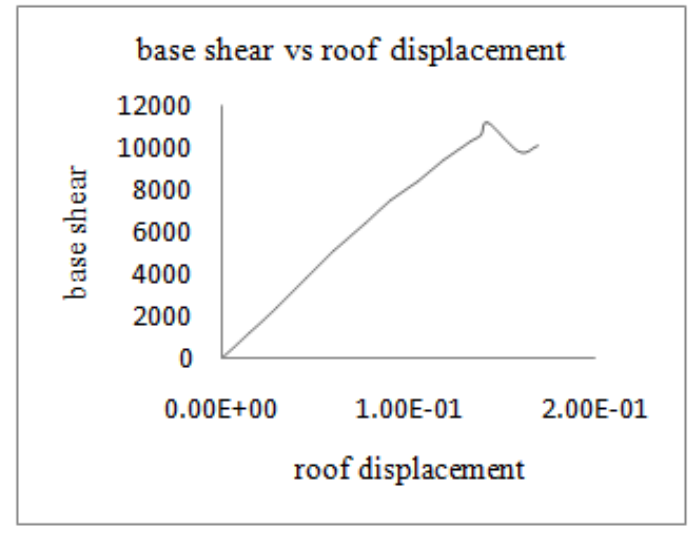

The above graph shows comparision between base shear and roof displacement for high rise structure with infill.

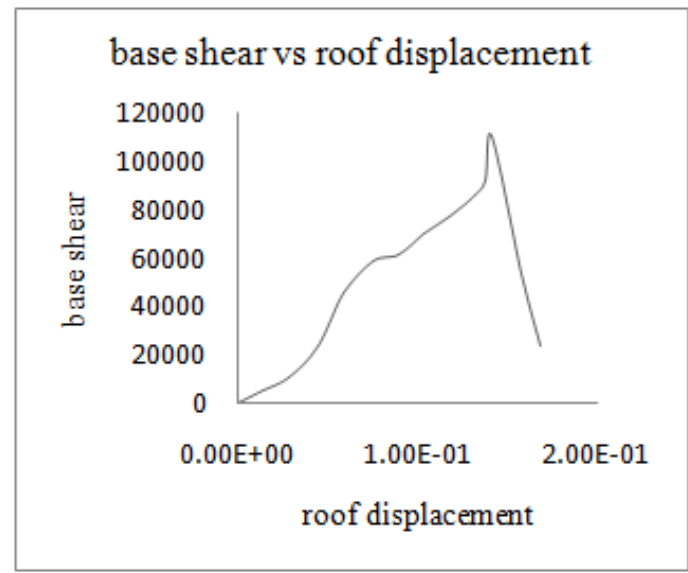

The above graph shows comparision between base shear and roof displacement for high rise structure with infill.

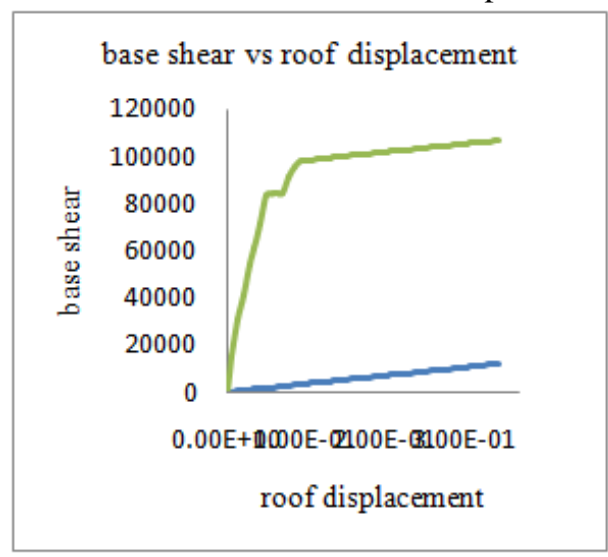

The above graph shows comparision between base shear and roof displacement for high rise structure with infill and without infill.

\begin{tabular}{|c|c|c|c|c|c|c|c|c|c|c|c|}
\hline \multicolumn{3}{|c|}{ Hinge damage states } & A-B & B-IO & IO-LS & LS-CP & CP-C & C-D & D-E & $>\mathbf{E}$ & TOTAL E \\
\hline \multirow[t]{2}{*}{$\mathrm{G}+4$} & Without infill & \multirow{2}{*}{$\begin{array}{l}\text { User } \\
\text { defined }\end{array}$} & 447 & 188 & 2 & 1 & 1 & 0 & 0 & 1 & 640 \\
\hline & With infill & & 580 & 91 & 7 & 1 & 0 & 1 & 0 & 56 & 736 \\
\hline \multirow[t]{2}{*}{$\mathrm{G}+8$} & Without infill & \multirow{2}{*}{$\begin{array}{l}\text { User } \\
\text { Defined }\end{array}$} & 1722 & 349 & 2 & 2 & 2 & 1 & 0 & 2 & 2080 \\
\hline & With infill & & 3156 & 311 & 56 & 9 & 4 & 0 & 0 & 256 & 3792 \\
\hline \multirow[t]{2}{*}{$\mathrm{G}+20$} & Without infill & \multirow{2}{*}{$\begin{array}{l}\text { User } \\
\text { Defined }\end{array}$} & 9210 & 1422 & 2 & 2 & 1 & 0 & 0 & 3 & 10640 \\
\hline & With infill & & 9210 & 1302 & 2 & 2 & 1 & 0 & 0 & 120 & 10640 \\
\hline
\end{tabular}

The table gives summary of hinge damage states 
The table above clearly shows the number of plastic hinges formed in the performance levels i.e., immediate occupancy(IO), life safety(LS), collapse prevention(CP).these performance levels indicated the structure's capability of withstanding the high magnitude earthquake.

\section{Results And Discussion}

A Static nonlinear push over analysis is carried out on the buildings under consideration. Their responses are monitored and push over curves are plotted.

\section{Low rise structure $(\mathbf{G + 4})$}

A comparison is done, for the structure with and without infill ,results are tabulated.

1. Load taken by the low rise structure with infill is almost ten times the low rise without infill

2. The displacement are more in low rise structure without infill when compared to low rise infill

\section{Mid rise $(\mathbf{G + 8})$}

1. Load taken by the midrise infill is almost ten times than mid rise without infill

2.Displacement are more when compared to infill .For a given load, displacements are more in without infill.

\section{High rise $(\mathbf{G + 2 0})$}

1. Load pattern is same as above mentioned ,loads taken by the with infill is ten times compared to without infill

2. Displacement is more in structure without infill.

Main considerations are listed below:

- First mode takes pre-dominant response of the structure.

- Modal periods and frequencies for bare frame and infill frame structures are compared, by introducing the infill to the RC structures, initial stiffness increases and there by reduction in natural time period. They take the axial loads and reduce the loads on the frames.

- For low rise structure mode 1 is taken into consideration for our study, since it takes pre-dominant response. The time period reduces by $26.86 \%$ in infill $\mathrm{w}$ hen compare to bare frame.

- Similarly for the mid rise structure time period reduces by $38.71 \%$ in infill when compared to without infill.

- For high rise structure, time period reduces by $41.03 \%$ in fill when compared to without infill.

Coming to the plastic hinges formation the infill's fail as they could not resist the maximum load, so more number of hinges form in structure with infill. By evaluating all these structures, we can conclude that infill structures take the maximum loads, and they resist the structures during earthquake. By using SAP 2000 software we can find the performance of the structure. The magnitude of base shear that can be resisted increases with increase in the number of bays. By using different methods structure is evaluated, by using FEMA 356 coefficient method ATC-40 Spectrum method, performance of the structure is evaluated. By knowing the performance point, we can observe the structural health, and how it should be monitored. As the stories goes on increasing steel reinforcement plays a significant role, so sufficient ductility should be provided to RC members to withstand the loads. Optimum steel reinforcement is provided as per the standards

\section{References}

[1]. Indian Standard ,IS 1893 : 1984, Indian Standard Criteria for Earthquake Resistant Design of Structures(Fourth Revision).

[2]. Indian Standard, IS $456: 2000$, Plain and Reinforced Concrete Code for Practice(Fourth Revision)

[3]. Indian Standard ,IS : 875 ( Part 2 ) - 1987 (Reaffirmed 1997) Code Of Practice For Design Loads (Other Than Earthquake) ,For Buildings and Structures ,Part 2 Imposed Loads (Second Revision) Six tll Reprint JUNE 1998.

[4]. ATC. Seismic evaluation and retrofit of concrete buildings—volume 1 (ATC-40). Report No. SSC 96-01. Redwood City (CA): Applied Technology Council; 1996.

[5]. FEMA. NEHRP guidelines for the seismic rehabilitation of buildings (FEMA 273). Washington (DC): Building Seismic Safety Council; 1997.

[6]. Plastic Hinge Length in Reinforced Concrete Flexural Members by Xuemei Zhao1a, Yu-Fei Wu1b, A.Yt. Leung1 and Heung Fai Lam11Department of Building and Construction, City University of Hong Kong, China.

[7]. Bae SJ and Bayrak O (2008). Plastic Hinge Length of Reinforced Concrete Columns. ACI Structural Journal, V. 105, No. 3, May June1

[8]. Optimal seismic performance-based design of reinforced concrete buildings using nonlinear pushover analysis X.-K. Zou, C.-M. Chan* Department of Civil Engineering, Hong Kong University of Science and Technology, Kowloon, Hong Kong, China

[9]. Seismic Analysis of High-Rise Open Ground Storey Framed Building by Krushna B. Avhad.

[10]. [10] modeling of masonry infill panels for structural analysis By a. Madan,t a. M. Reinhorn,2 fellow, asce, j. B. Mander,3 member, asce, And r. E. Valles4

[11]. [11] Code Approaches to Seismic Design of Masonry-In filled Reinforced Concrete Frames: A State-of-the-Art Review Hemant B. Kaushik,a... Durgesh C. Rai,b... M.EERI, and Sudhir K. Jain,c... M.EERI 